www.jmscr.igmpublication.org

Index Copernicus Value: 79.54

ISSN (e)-2347-176x ISSN (p) 2455-0450

crossref DOI: https://dx.doi.org/10.18535/jmscr/v7i5.39

\title{
Diagnostic study of Intra-hepatic Space Occupying Lesions
}

\author{
Authors \\ Dr Rajesh Paswan, MD (Radiodiagnosis) ${ }^{1}$, Dr Rahmat Ali, MS (Ortho), (MCh. Ortho) ${ }^{2^{*}}$ \\ ${ }^{1}$ Consultant, Combined District Hospital, Sant Kabir Nagar \\ ${ }^{2}$ Associate Professor, Dept. of Orthopedics, Autonomous State Medical College Basti \\ *Corresponding Author
}

Dr Rahmat Ali, MS (Ortho), (MCh. Ortho)

Associate Professor, dept. of Orthopedics, Autonomous State Medical College Basti

\begin{abstract}
This paper depict the role of sonography in diagnosis of intra-hepatic space occupying lesions sonography is considered to be most cost effective priming investigation of choice in evaluation of liver mass \& right upper abdominal problem Ultrasound is safe simple of non invasive investigation. It can be applied in the patient with jaundice also. Ultrasonography can provide information regarding the nature of the lesion also. It is particularly useful in distinguishing solid lesion from cystic. In the diagnosis of cystic lesions Ultrasonogrphy has been called on unrivalled the extent of the disease and pattern of involvement of liver parenchyma also determines by sonography.

Keywords: Intra-hepatic space occupying lesion, Rt. upper quadrant swelling, Hepatic SOL, Simplex x-ray, Hepatic angiography, Isotope scanning, Biopsy/FNAC, Computed tomography, Ultrasound.
\end{abstract}

\section{Introduction}

Intra-hepatic space occupying lesions are frequently encountered in clinical practice \& often pose difficult problem in diagnosis. A vast majority remains asymptomatic in early stages. Nevertheless, it is responsible for a variable degree of non specific symptoms such as fever malaise, nausea, anorexia, weightless, abdominal discomfort, awareness of lump in abdomen etc. the clinical signs of liver disease such as jaundice and hepatomegaly are not only non-specific but are late appearing in clinical course of many cases of space occupying lesions. We have following radiological procedure for the disease of intrahepatic space occupying lesions.

\section{Various diagnostic methods used}

Simple x-ray- Being the bulkiest Body organ the liver cast on appreciative shadow on radiograph through modify by individual variable of shape and orientation only. these locative mass are detected on plan x-ray which are lying adjacent to or deform one of the visible linear border or came a change in on adjacent structure such as diaphragm (tenting and for elevation) many hydatid classify the appearance reseating a crumpled eggshell. Primary liver carcinoma may occasionally be manifest by either faint stippled calcification or very rarely 'sunburst' type calcification old abscess and granuloma may also calcify and may be multiple generalized increased radiodencity of liver occur in haemochromatosis. 
Hepatic angiographry- This performed by transfemoral percutaneous catheristion of the celiac axis or super selective catheterization of the hepatic artery and injection of $30 \mathrm{mls}$ bolus of contrast radio with this technique it is possible to demostrate both primary \& secondary tumor of the liver. Isotope scanning the gamma emitting isotope such as 198 colloidal gold and technitinm is taken up by the raticuloendthilial system and useful in focal lesions is liver. Te demonstration of the liver by isotope scanning technique following injection of radioactive isotope is now widely practiced. Tumors and benign lesion such as cysts usually show on the scan as cold areas ie areas of absent or diminished isotope uptake.

Computed tomography - Computed tomography rapidly established itself as a valuable technique for showing either focal or differs pathologies of the liver either focal or difference well shown by CT scanning. Specific diagnosis can be made immediately in such difference lesions as fatty infiltration of haemochromatosis Focal lesions in the liver one usually well demonstrated and contrast enhancement may and diagnosis where the findings are equivocal or non specific. These is a high degree of accruing in the demonstration of malignant tumors primary of secondary and in showing such lesions cysts or abscess.

Biopsy- tissue obtaining under image control is now a frequent interventional procedure. The more usual indication is accurate Biopsy of a localized region or pathology.
Ultrasound- Ultrasound particularly the use of real time gray scale lesion the liver fan now the quite well shown. Ultrasonic waves also require some medium for their transmission and cannot be transmitted in vacuum. Frequencies between 2-16 $\mathrm{MHz}$ are used for diagnostic purposed. When Ultrasonic waves are passed through body tissue by direct contain echoes produce off from different body material interface are received by transducer which is act both as emitter as well as receiver of the ultrasonic waves. Ultrasonic waves in the transducer are produced by high frequency pulsed vibration of naturally occurring or Ceramic crystals. This phenomenon is called piezoelectric effect. The reflected echoes in the transmitter are converted into electrical impulses which are tram farmed by electronic techniques to image by real time gray scale ultrasonography to be displayed on monitor.

Radiological contras procedures like angiography, are invasive and not without a certain element of risk to the patient, Even liver biopsy and laprotomy have limitations in diagnosis metastasis in the liver. According to conn (1972) needle biopsies fart to detect existing liver metastases in at least $25 \%$ of causes. While it is estimated that more than $18 \%$ of the liver metastases are missed even at laprotomy (ozards nad pickren, 1962) The ultrasonographic Pattern of various spaceoccupying Processes in the liver described.

\section{Classification}

Space -occupying lesions of the liver which are commonly encountred may be classified as follows:

I congenital

Single

Simple cyst

II Acquired

(a) Inflammatory

Abscess

Bacterial

Parasite

Actinomycotic

(b) Traumatic

Granuloma

Laceration
Multiple

Polycystic disease

Abscesses

Granulomata 

(c) Degenerative
Amyloidosis
Cirrhosis
Cirrhosis.

(d) Neoplastic

$\begin{array}{lll} & \text { Benign } & \text { Adenoma. } \\ \text { Malignant } & \text { Haemengioma } & \\ & \text { Hepatoma } & \text { Hepatomas } \\ & \text { Lymphoma } & \text { Lymphomata }\end{array}$

Secondaries

(Adopted from Mc Cready V. Ralph,1972)

\section{Ultrasonic Patterns of Different Space- Occupying Lesions}

The ultrasonographic pattern of various spaceoccupying processes in the liver described.

Hepatic abscesses: the appearance will vary according to the type of abscess and the stage in its evolution at which it is examined. In general they have thick irregular wall and contain a variable amount of debris the proportion of fluid present varies greatly.

\section{Malignant tumors of the liver}

Hepatocellular carcinoma (HCC) is the most common malignant tumours, accurs predominary in men with sex ratio of approximately 5:1. (Kew M C et .al. 1982 and Johnson CD et. al. 1996). Echogenic metastases tend to arise from a gastrointestinal origin or from hepatocellur carcinoma. Also more vascular the tumor more likely the lesion to be echogenic (Tanaka $\mathrm{S}$ et al. 1990).

The appearance on sonography are varies. Focal lesions predominate producing non-specific mass effect characteristic alteration in echo properties often occur in tumours of the liver. The most common are rounded foci of decreased of increased reflectivity with rather ill-defined marging and normal attention, sometimes randomly distributed within 1 lesions, but often arranged concentrically, with a cortex of relatively anechoic tissues arranged around a more relective central core. This pattern is commonly referred to as the "target" or "bull's-eye" lesion Tomours with fluid characteristic are also encountered. When truly cystic, they are wechofree have smooth walls and show distal echo enhancement.
This pattern seen is lesion walls are useual irregular and the necrotic material may produce irregular low level echoes. When there I massive replacement of live with tumour, the nodules coalesce and the sonogram develops a Widespread patchy texture in which it may be difficult to judge which portions represent normal liver and which are tumour. Tumours in the liver occasionally take the form of numerous millimeter-sized foci which are evenly distributed throughout the parenchyma and are known as military metastases. On ultrasonography, this produces a fine echo texture which is nonspecific. In the case of lymphomas, lymphocyte infiltration may produce a uniform reduction in echo levels. Calcification produces extremely intense echoes with strong distal shadowing Sarromata usually return very low levels of echoes and sometimes show distal enhancement, apparently in the absence of necrotic or cystic change (Goldberg, 1981).

\section{Hepatic cysts}

Cysts of the liver have 3 features on ultrasonography (Hebert and Galinas, 1975.

1. Sonolucency- due to the fact that the liquid content gies to cysts a homogenous, interface, internal structure.

2. Sharp boundary- due to great impedance difference between their walls and the surrounding tissues on the one hand and their fluid content on the other.

3. Positive posterior echo accumulation- due to the face that Liquids do not attenuate the ultrasound beam. Thus the beam is 
sharply reflected by the interfaces beyond the cyst.

Hydatid cysts: These typically appear as anechoic lesions with sharp borders and good through transmission They may have lamellated walls and may contain debris. Daughter cysts, if present are virtually pathognomonic. Old inactive cysts may appear entirely simple and be indistinguishable from developmental cysts. Niron et al.(1981). Have described the ultrasonic features in 65 hydatid cysts removed from 38 patients. They divided the ultrasonic features into three groups. The first group (40 cysts) demonstrated the most commonly seen features- spherical shape, clearly defined outline, unilocular and completely anechoic. The second group showed less common features.

\section{Benign tumours of the liver}

Benign tumours of the liver are relatively uncommon hemangiomas being the most common.

\section{Cavernous haemangioma}

Benign hepatic neoplasms are rare with the exception of the Cavernous haemongioma. This is most common benign tumour of the liver. The tumour is composed of a network of vascular endothelial lined spaces filled with blood. The majority are entirely asymptomatic and require no treatment.

The spectrum of appearance on ultrasound is variable. However, the majority have a very distinctive pattern. This is of a sharply defined, highly reflective round tumour usually less than 2 $\mathrm{cm}$ in diameter and with homogenous echo pattern which is almost always subcapsular in position or closely related to the hepatic veins. The mass is lobulated and often contains large anechoic areas corresponding to venous and often contains large anechoic areas corresponding to venous lakes. A fine network of anechoic lines may be seen throughout the mass, corresponding to large vessels. The diameter of haemangiomas varies from few millimeters to $10 \mathrm{cms}$ and they are multiple in approximately 15 percent cases.
Haemmangiomas larger than $2.5 \mathrm{~cm}$ in diameter are reported to show posterior acoustic enhancement. This is an unusual feature although not unique in highly reflective masses and probably relates to the vascularity (Taourg J.et al.1983).

Capillary hemangiomas return very densely packed, high level echoes. They may calcify and cause acoustic shadowing.

\section{Liver cell Adenomas}

Liver cell adenoma consists of normal or slightly atypical hepatocytes containing areas of bile stasis and focal haemorrhage or necrosis. These are most frequently seen in women and on association with oral contraception has been described. Most adenomas are vascular hence strongly echogenic and show enlarge feeder vessels. Spontaneous internal haemorrhage is common, pain in right upper quadrant may be the presenting symptom. Areas of haemorrhage will appear as cavities or poorly echogenic areas; usually centrally placed within the mass most adenomas are sharply circumscribed, often showing a discrete capsule. This is rarely more than $6-7 \mathrm{~cm}$ diameter. The ultrasound features are variable. The lesions are usually homogenous with a slightly doddering reflectivity to the normal liver which may be higher or lower. The only characteristic feature in septation within the mass with a central strongly echogenic scar or nidus.

The excellent blood supply haemorrhage, necrosis and calcification rare in focal Nodular hyperplasia (Saul SH, et al. 1996).

Cystic mesenchymal hamartomas and Lymphangiomata appear as large, fluid masses with lacy septa.

Pseudotumours of cirrhosis are difficult to detect ultrasonographically since the tissue concerned is very similar to normal live tissue.

\section{Benign focal Liver Lesions}

Liver heamatoma: The aetiology of the liver haemotoma may be blunt abdominal trauma or rupture of a neoplasm such as a hepatic adenoma or cavernous haemangioma. In children blunt abdominal trauma causing liver trauma is a 
common problem. This may be attributed to the greater flexibility of the rib cage and the lack of surrounding fat. (Kawashima A., et al.1986).

\section{Accuracy of Ultrasonography}

The minimal focal lesion that can be detected by ultrasonography is said to be about 1-2 cms. (Goldberg, 1981).

Wang et al. (1964) reported that in 218 hepatic abscesses studied ultrasonographically, 212 (97.2 percent) produced the typical change; and 207 (95 percent) were correctly interpreted. In 2 other series reported 21 out of 22 hepatic abscesses (Viary, 1975) and 15 out of 17 amoebic abscesses (Piyachon, 1978) were correctly interpreted.

Rubinson et al.(1980) have reported a sensitivity of 75 percent in diagnosing hepatic abscesses by ultrasonography.

\section{Sources of error in hepatic ultrasonography}

Normal structures that may be confused with focal lesions include the highly reflective round ligament, diaphragmatic leaflets lying in "cough furrous" on the dome of the right lobe of the liver, the upper pole of the right kidney or its perinephric fat and fascia, and shadows distal to the porta and the neck of the gall bladder (Goldberg, 1981).

The liver is poorly visualized in some patients whose small livers do not project below the costal margin even on deep inspiration. The anterolateral portion of the right lobe of the liver is also sometimes difficult to evaluate due to interference from overlying ribs (Bryan et al. 1974) the dome of the right lobe under the rib cage may also be inaccessible (Leyton et al., 1973) Moreover, excessive obesity, bowel gas, patient motion, surgical wounds and dressings may all interfere with ultrasonography (Wistow and Grossman, 1979)

\section{Methodology}

The present study was conducted in the department of Radio diagnosis of Darbhanga Medical College \& Hospital Laheriasarai on one Hundred patient. The material for the study consisted of patients from Department of Medicine and Surgery of this hospital with a provisional diagnosis of space occupying lesion of the liver were included in the study.

\section{Analysis}

The diagnosis of intra-hepatic Space occupying lesions is often difficult because of the frequent non-specific result of the clinical Examination and tests of liver function in patient with such lesions. Hepatic ultrasongraphy is a technique with important application in such lesions.

The study was therefore carried out to evaluate the result of Ultrasonography in seventy patient in whom the diagnosis of Intra-hepatic space occupying lesions was proved by other means aspiration of pus (Amoebic liver abscess) casoni`s test, laprotomy (Hydatid Cyst), liver biopsy/FNAC (Tumors of the liver). Ultrsonography diagnosis of polycystic liver disease and simple liver cyst was taken as find confirmation.

Age Distribution: The age of seventy patents ranged from 22 years to 78 year. The age of 40 patients with amoebic liver abscess ranged from 22 year to 70 years. The peak incidence of the causes was fourth decade, since the patients with amoebic liver abscess comprised a large group, was Considerably influenced by this group. This is in conformity with earlier reports. Plords (1977) has reported that amoebic liver abscess occurs predominantly in third to fifth decades.

Habibullah et.al. (1977) in a study of 110 cases of amoebic liver abscess found that the high-test incidence was in the 4th decade which is also true of our series (18 of our 40 patients of amoebic liver abscess were group of 31-40 years)

Sex Distribution: Our series of seventy patients included fifty five males \& fifteen females, In the amoebic liver abscess group there were Thirty five males \& five females. Seven of nine patients with hydatid Cyst were females while of thirteen patient with metastatic disease were females. The five patient with hepatoma and two patients with 
polycystic liver \& one patient with simple Cyst of liver were all males.

Ultrasonography: Ultrasonography Examination revealed space occupying lesions in sixty six of the Seventy patients with proven intrahepatic space occupying lesions the sensitivity of hepatic ultrasonography in the prevent series was $94.28 \%$ space occupying lesions were missed in four patient giving false negative rate of $5.72 \%$.

Amoebic liver abscess: In proven 40 cases amoebic liver abscess 36 of these patients were demonstrated on ultrasonogrphy in all these patients the space occupying lesion were diagnosed as abscess became of their sonographic appearance. They were seen as amoebic liver abscess with variable amounts of scattered internal echoes which are sometimes seen at high gain settings. The size of abscess ranged from $4.5 \mathrm{~mm}$ to $16.5 \mathrm{~mm}$ in longer diameter. The space was round ov or oval. Twenty four patient had a single abscess ten had two abscess while two patients had three abscess. Walls were irregular in twenty, while three were fair by thick and smooth in seventeen. Thus, the sensitivity of Ultrasonography in diagnosis of amoebic liver abscess was $92.50 \%$ with false negative rate of $7.50 \%$.

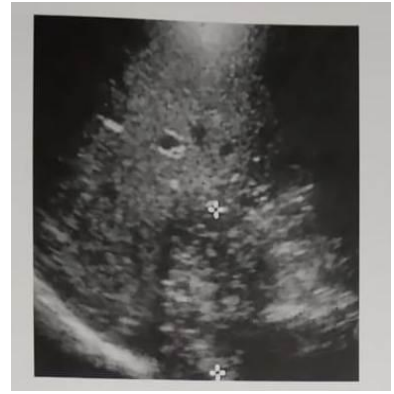

Fig. 1 Liver Abscess.

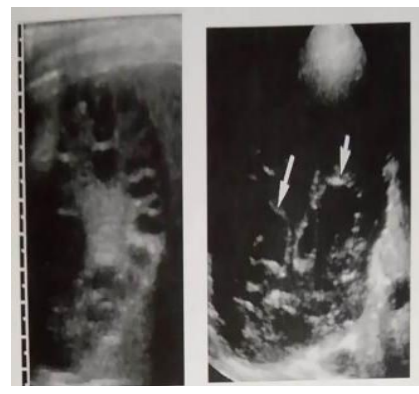

Fig. 2 \& 3 Hydatid cyst.

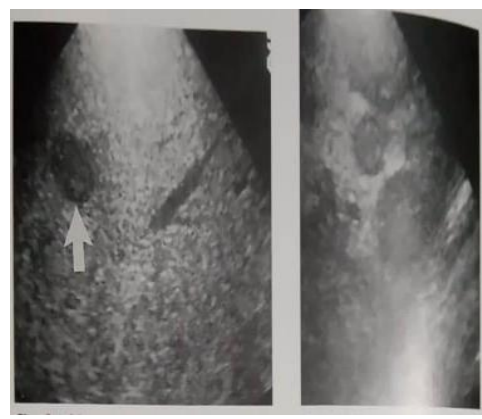

Fig. 4 \& 5 Liver Metastasis.
Malignant Hepatic Tumors: - The present series induced 18 patients with malignant tumor of the liver. They include 13 patients with metastasis and five patients with hepatoma. The ultrasonographic appearance were variable, there were nondistinguishing features is the appearance seen with metastasis and those with hepatomas. Multiple small hypo echoic lesions were seen in four patients. The dilated intra-hepatic ducts were seen in four cases.

Thus the present series included 18 patient with malignant tumor of the liver. Ultrasonography successfully detected the lesion in 17 of 18 patient giving sensitivity of $94.44 \%$ with the false negative rate of $5.56 \%$.

Cysts of the liver: Our series of seventy patient with Intra-hepatic space occupying lesions included 9 cases of hydatid cyst, 2 cases of polycystic liver and 1 cases of simple cyst of liver.
Ultrasonography Successfully detected space occupying lesions in all there 12 patient giving sensitivity rate of $100 \%$ out of nine patients of the hydatid cyst solitary cyst were seen in 3 cases while 6 patient had multiple cysts involving with lakes. The cyst were seen as son lucent areas with no internal echoes.

All had smooth wall, distal enhancement was also present.

\section{Conclusion}

Ultrasonography is useful \& noninvasive technique with a high degree of sensitivity in the detection of Intrahepetic space - occupying lesion. Ultrasonography is very useful in cases of

(i) Acute stage of the disease

(ii) Patients with Jaundice

(iii) Patients with gastrointestinal abnormality 


\section{(iv) Pregnancy \\ (v) Severely ill patients}

One hundred patients with probable diagnosis of space-occupying lesion of liver were studied. Complete physical examination, Hemogram (total Leucocyte count, different of Leucocyte count , $\mathrm{Hb}$ percent) and liver function test, kidney function test were performed, Radiological examination plain skiagram of chest, Plain X-ray abdomen was arrived out when needed. Aspiration of pus was performed in paitent with amoebic liver abscess. A therapeutic response to a full course of metronidazole was considered corroborative evidence for the diagnosis of amoebic liver abscess. Liver biopsy/FNAC was done in patient with suspected hepatic tumor. Ultra sonography had sensitivity of 94.28 percent with false negative rate of 5.72 percent. The result of Ultrasonography were evaluated in there seventy patient with detention of space occupying lesion in sixty six patients. USG fail to detected SOL in three patient of amebic liver abscess \& One patient of metastatic lesions characterizations of the lesion was possible with ultrasonography

\section{Reference}

1. Akhan O, Ozem MN, Dincer A, et al. Liver hydatid disease long term result of percutaneous treatment Radiology 1996,198 258-264

2. Abul-Khair, Mehmood Holmy, Kenewi, Mohammad H, Koreshy, Ezz EL-Din A and Arafe, Mabil M. Ultrasonography and amoebic liver absceses. Ann Surg. 193 221-226,1981.

3. Altree, $M$ : Scanning in hydatid disease. Clin Radiology 30 : 691-697, 1979.

4. Babcock DS, Kaufman L, Cosnow I, Ultrasound diagnosis of hydatid disease AJR 1978,138:895

5. Bernordine, Michael E., Thomas, John I and Mehled, Nabil, Hepatic sonography : Technical considerations, present applications and possible future, Radiology 142 : 249-251, 1982.
6. Begis, I.N. and Upyrer, Combined application of radioisotope scanning and ultrasonics in the diagnosis of liver disease.Vestn Khir. 99 : 25, 1967.

7. Baily and Love Short Practice of Surgery $21^{\text {st }}$ Edition, (1991).

8. Bryan, Patrick J., Dinn, W.M., Grossman, Z.D., Wistov, B.W., AcAfee, J.G., Kieffer, S.A. Correlation of computed tomography, gray-scale ultrasonography, and radionuclide imaging of the liver in detecting, and radionuclide imaging of the liver in detecting space-ocupying processes, Radiology 124:387-393,1977.

9. Conn, H.O Rational use of liver biopsy in the diagnosis of hepatic cancer. Gastroenterology 61:142-146,1972.

10. Conn, H.O. and Elkington, S.G. : Is hepatic scanning over-rated Gastroenterology 45:136-140, 1968.

11. Cavington, E Engene : Patfalls in liver photoscans. A.J.R. 109. 745-748, 1970.

12. Dabongaia, J.C., Pauls, C., Fievac, N.and Wibbin, E. : Prospective evaluation of the diagnostic accuracy of liver ultrasonography. Gut 22(2) : 130-135,1881.

13. David Sutton, Text Book of Radiology and Imaging Vol. 2, Sixth edition(1998).

14. David Cosgrove, Abdominal and General Ultrasound, Vol.1, 1993.

15. Donald, I., AcVicar, J and Brown, T.G. : Inverstigation of abdominal masses by pulsed ultrasound. Lancet I : 11851195,1956.

16. Dubbins, P.A. O'Rirdan, D. and Nells, W.H. Ultrasound in hepatoma- Can specific diagnosis be made ? Dr. J. Padiel, 84, 307-311, 1981.

17. Fee H.J., Precher, R.K., Cameron, J.L. and Vagner, H.N. Liver scanning in patients with respected abdominal tumour. J.A.M.A. $230:$ 1675-1677,1974.

18. Farrier, F.L., Hatcher, C.R., schord, J.L. The value of liver scanning for detection 
of metastatic cancer. Ann. Surg. 35 : 11212,1969 .

19. Charbi Hasser A., Hessine Wahid, Brouner Michael W. and Dupuch Kathelyn : Ultrasound examination of the hydatic liver. Radiology 139: 459-463,1981.

20. Goldberg Barry B : Abdominal gray-scale ultrasonography, pp. 1-16 and 103-136, Wiley, New York, 1977.

21. Goldberg Barry B. : Ultrasound in cancer, pp. 1-21, Churchill Livingstone, New York, 1981.

22. Gollin, F.F., Sie, J LeR. And Camerron, J.R. : Liver scanning and function tests, a comparative study J.A.H.A. 187 111-116, 1964.

23. Green Darry, Bree Robert L., Godstein Harvey N. and Stanley countney : Grayscale ultrasound evaluation of hepatic neoplasms : Patterns and correlations. Radiology 124. 203-208, 1977.

24. Grossman Zochary D., Wistow Brien W, Bryen Patrick J, Dinn W. Martin, McAfee John G. and Kieffer Stephen A. Radionuclide imaging, computed tomography and gray-scale ultrasonography of the liver- a comparative study, J Nucl Mod. 18: 327-332, 1977.

25. Habibullah, C.M. and Padmanabhna, C.G. : Ultrasound imaging in amoebic liver abscess and hydatid cyst of the liver. Trep. Gastroenterol, 2(3) : 179-175,1981.

26. Habibullah, C.H., Oureshi, .Afsol, Chandra Vinod, Padmanabhna, C.G., Kumar Nareeh and Agarwal Devi : liver scan in amoebic liver abscess. J. Assec. Phy. Ind . 25:593-596, 1977.

27. Hedidi Ali : sonography of hepatic echinococcal cysts Gostrointest. Rediol. 7: 349-354,1982.

28. Hassani Nasser : Ultrasonography of the abdomen, pp . 1-30, Springer- vorlay, New York, 1976.

29. Hebert Guy and Gelinas Claude : Hepatic echography. A.J.R . 125: 51-59, 1975
30. Holm Hans Hondrick : Ultrasonic scanning in the diagnosis of spaceoccupying lesions of the upper abdomen. Br. J. Radiol. 44:24-36, 1971.

31. Howry, D.H. and Bliss, W.R: Ultrasnonic investigation of soft tissue structures of the body. J. Lab Clin. Mod. 50-579-592, 1952.

32. Johnson CD : Imaging of hepatocellular carcinoma, In Freeny PC, editor : Radiology of liver, Billiary tract and Pancreas, sanDiego; ARRS Categorial course syllabus $199696^{\text {th }}$ Annual Meeting.

33. Kegan, I.G. : The immunology of amoebiasis. Arch. Inv. Med. (Hex.) 5 Supply. 2: 467-460, 1974

34. Kamin Paul D., Eornardino Michael E. and Green Barry : Ultrasound manifestations of hepatocellular carcinoma. Radiology $131:$ 459-461,1979.

35. Kawaski Hronska, Sagoguchi soihe, Irisa Toshitake and Hiragama Chiseto : Value of b-scan ultrasonography in the diagnosis of liver cancer. Amer. J. Gastroenterol. 69:456-442,1978.

36. King Donald L. Diagnostic ultrasound, pp. 1-51 and 260-272, C.V. Mosby Company, 1974.

37. Kuni C.C, Johnson NL, Holmes JH, Polycystic liver disease, JCU 1978,6: 332

38. Kurdziel JC, Itines J, Parache RM, Chaulieu C. Adenolipoma of liver a unique case with ultrasound and CT pattern. Eur J. Radiol. 1984, 53 : 440.

39. Kuligowska Ews, Connors Seean K., shapire Jeroe H. : Liver abscess : sonography $\mathrm{n}$ diagnosis and treatment. A.J.R. 138:253-257,1982.

40. Leyton, B., Helpern, S., Leopold, G. and hagen, S. : Correlation of ultrasound and colloid scientiscan studies of the normal and diseased liver. J . Nucl . Med . 14:27231973.

41. Lempence, A., Line, P., Halpoern, S, and Leopeld, G: Nuclear Medicine and Ultrasound: Correlation in diagnosis of 
diseases of the liver and biliary tract.

Semin. Nucl. Med. 5 : 307-324,1975.

42. Lubin, E. and Levitun, Z : Blood pool scanning in investigating hepatic masses. Semin. Nucl. Med. 2 : 128-132, 1977.

43. Ludbrook, J., Slavonitek, A.H. and Ronai, P.H. : Observer error in reporting on liver scans for space-occupying lesions. Gastroenterology, 62: 1013-1018,1972.

44. Lathewa, A.H., Cough, K.R., Device, E.R., Ross, F.G.M. and Hincliffe, A. : the use of combined ultrasound and isotopescanning the diagnosis of amoebic liver disease. Gut. 14:50-53,1973.

45. Mc Cready V. Ralph. : scientigraphic studies of space-occupying liver disease. Somin. Nucl. Med. 2 : 108-127, 1972.

46. Muire Hylton B. : Diagnostic ultrasound, Br. J. Radiol. 62: 665-703, 1979. Newlin Nancy, silver Terry M., Stuck Naren J. and Sandler Michael.

47. M.: ultrasonic features of pyogenic liver abscesses. Radiology, 139 : 155-159,1981.

48. Niron, E.A. and Oror, H. : Ultrasound appearances of liver hydatid disease, $\mathrm{Br}$. J.Radio. 54:335-338, 1981. 